\title{
Hyperactive Behavior and Altered Brain Morphology in Adult Complement C3a Receptor Deficient Mice
}

\author{
Andrea Pozo-Rodrigálvarez ${ }^{1}$, Roosa Ollaranta ${ }^{1}$, Jenny Skoog ${ }^{1}$, Milos Pekny ${ }^{2,3,4}$ and \\ Marcela Pekna ${ }^{1,3,4 *}$
}

${ }^{1}$ Laboratory of Regenerative Neuroimmunology, Department of Clinical Neuroscience, Institute of Neuroscience and Physiology, Sahlgrenska Academy at the University of Gothenburg, Gothenburg, Sweden, ${ }^{2}$ Laboratory of Astrocyte Biology and CNS Regeneration, Department of Clinical Neuroscience, Institute of Neuroscience and Physiology, Sahlgrenska Academy at the University of Gothenburg, Gothenburg, Sweden, ${ }^{3}$ Florey Institute of Neuroscience and Mental Health, Parkville, VIC, Australia, ${ }^{4}$ University of Newcastle, Newcastle, NSW, Australia

\section{OPEN ACCESS}

Edited by:

Jorge Matias-Guiu,

Complutense University of Madrid, Spain

Reviewed by:

Ulises Gomez-Pinedo, Instituto de Investigación Sanitaria del Hospital Clínico San Carlos, Spain

Alejandro A. Canales-Aguirre CONACYT Centro de Investigación y Asistencia en Tecnología y Diseño del Estado de Jalisco (CIATEJ), Mexico

${ }^{*}$ Correspondence: Marcela Pekna marcela.pekna@neuro.gu.se

Specialty section

This article was submitted to Multiple Sclerosis and Neuroimmunology, a section of the journal Frontiers in Immunology

Received: 10 September 2020 Accepted: 01 February 2021 Published: 22 February 2021

Citation: Pozo-Rodrigálvarez A, Ollaranta $R$ Skoog J, Pekny M and Pekna M (2021) Hyperactive Behavior and Altered Brain Morphology in Adult Complement C3a Receptor Deficient Mice. Front. Immunol. 12:604812. doi: 10.3389/fimmu.2021.604812
The C3a receptor (C3aR) is a seven trans-membrane domain G-protein coupled receptor with a range of immune modulatory functions. $\mathrm{C} 3 \mathrm{aR}$ is activated by the third complement component (C3) activation derived peptide C3a and a neuropeptide TLQP-21. In the central nervous system (CNS), C3aR is expressed by neural progenitors, neurons as well as glial cells. The non-immune functions of $\mathrm{C} 3 \mathrm{aR}$ in the adult CNS include regulation of basal neurogenesis, injury-induced neural plasticity, and modulation of glial cell activation. In the developing brain, $\mathrm{C} 3 \mathrm{aR}$ and $\mathrm{C} 3$ have been shown to play a role in neural progenitor cell proliferation and neuronal migration with potential implications for autism spectrum disorder, and adult $\mathrm{C} 3 \mathrm{aR}$ deficient $\left(\mathrm{C}_{3} \mathrm{a} \mathrm{R}^{-/-}\right)$mice were reported to exhibit subtle deficit in recall memory. Here, we subjected 3 months old male $\mathrm{C}_{3} \mathrm{a} R^{-1-}$ mice to a battery of behavioral tests and examined their brain morphology. We found that the $\mathrm{C} \mathrm{a} \mathrm{R}^{-/-}$mice exhibit a short-term memory deficit and increased locomotor activity, but do not show any signs of autistic behavior as assessed by self-grooming behavior. We also found regional differences between the $\mathrm{C}_{3} \mathrm{a} \mathrm{R}^{-/-}$and wild-type (WT) mice in the morphology of motor and somatosensory cortex, as well as amygdala and hippocampus. In summary, constitutive absence of C3aR signaling in mice leads to neurodevelopmental abnormalities that persist into adulthood and are associated with locomotive hyperactivity and altered cognitive functions.

\footnotetext{
Keywords: autism spectrum disorder, attention deficit hyperactivity disorder, C3aR, the complement system, neurodevelopment
}

\section{INTRODUCTION}

The complement system is a powerful effector of the innate immune system. C3aR is a seven trans-membrane domain G-protein coupled receptor expressed on myeloid cells as well as several types of non-myeloid cell types (1) and exerts a range of both pro-inflammatory and antiinflammatory functions (2). C3aR is activated by C3a, a $9 \mathrm{kDa}$ fragment generated by the proteolytic cleavage of the third complement component (C3) (3), and a vascular growth factor-derived neuropeptide TLQP-21 (4). In the brain, C3aR is expressed by neural progenitor cell $(5,6)$, neurons (7-10) as well as glial cells $(7,8,11-13)$. 
The non-immune functions of C3aR in the adult CNS include regulation of basal and ischemia-induced neurogenesis $(5,14)$, synaptic strength and dendritic complexity (15), neuroprotection (16), injury-induced neural plasticity (17), and modulation of glial cell activation (13, 18); reviewed in (19). In vitro, C3a modulates migration of neural progenitor cells and stimulates their neuronal maturation (20). In the developing brain, C3aR plays a role in neural progenitor cell proliferation (6), and $\mathrm{C} 3 \mathrm{aR}$ and $\mathrm{C} 3$ cleavage products are required for normal neuronal migration (21), which is an essential process for normal brain formation and establishment of neural circuits. Disturbed complement activity disrupts migration of pyramidal neurons from the ventricular zone to their correct laminar position in the cortical plate, leading to disordered layering of the developing cortex. This developmental defect can be rescued by pharmacological activation of C3aR (21). Deficiency of C3 results in reduced activity of small GTPase Rac1, with consequent cell cycle defects and premature neuronal differentiation (22). Given that $\mathrm{C} 3 \mathrm{aR}$ activation by $\mathrm{C} 3 \mathrm{a}$ was shown to regulate Rac1 activity in migrating crest cells (23), the regulation of Rac1 activity by C3 in migrating neurons is conceivably mediated through the $\mathrm{C} 3 \mathrm{a}-\mathrm{C} 3 \mathrm{aR}$ signaling. The neurodevelopmental functions of $\mathrm{C} 3 \mathrm{aR}$ signaling may thus be relevant for the understanding of cellular and molecular mechanisms underlying intellectual disabilities, schizophrenia, and autism (21). Indeed, adult $C 3 a R^{-/-}$mice were reported to exhibit subtle deficit in recall memory (6), but a detailed analysis of their behavior and brain morphology has been lacking.

The objective of the present study was to perform a more detailed investigation of the brain morphology of adult $C 3 a R^{-/-}$ mice, determine whether the previously reported disordered layering of the developing cortex due to disturbed C3aR signaling persists into the adulthood, and examine the behavior of $\mathrm{C} 3 a \mathrm{R}^{-/-}$mice with focus on locomotor activity, motor function, memory, and autism-like repetitive behavior.

\section{MATERIALS AND METHODS}

\section{Animals}

C3aR $R^{-/-}$mice (24) were backcrossed onto the C57BL/6J genetic background (Jackson Laboratories) for 10 generations. Heterozygous mice were then intercrossed to generate homozygous $\mathrm{C} 3 a \mathrm{R}^{-/-}$mice. WT $\mathrm{C} 57 \mathrm{BL} / 6 \mathrm{~J}$ mice served as controls. Male, 2-month-old mice were used. Mice were housed at Experimental Biomedicine (EBM), Sahlgrenska Academy, University of Gothenburg with a $12 \mathrm{~h}$ light/dark cycle and free access of food and water. All animal experiments were conducted according to protocols approved by the Gothenburg Ethics Committee.

\section{Open Field}

Mice were individually placed in the square arena, and allowed to explore the apparatus for $10 \mathrm{~min}$ while they were recorded to study their locomotor and exploratory activities (25). The arena was divided in 16 equal areas, considering the four central squares (25\% of the total arena) as the central zone and the surrounding areas as the peripheral zone. The parameters measured during the duration of the stay were speed $(\mathrm{cm} / \mathrm{s})$, activity, defined as the fraction of time in which the speed exceeded $0.2 \mathrm{~cm} / \mathrm{s}$, total distance covered in each zone $(\mathrm{cm})$, the number of rearings, and the number of grooming episodes. The data were analyzed with the Viewer ${ }^{3}$ video tracking system (Biobserve, Bonn, Germany).

\section{Object Recognition}

The object recognition test is based on the innate preference of mice to explore a novel object rather than a familiar one. The test was performed as previously described (25). Mice were habituated to the room 3 days before the test. During the familiarization session, two identical objects were used. Six hours later one of the objects was replaced by a different one for the short-term memory (STM) assessment. Twenty four hours later, long-term memory (LTM) was assessed by replacing the same object with a novel one. During each session, the mice were free to explore the objects for $10 \mathrm{~min}$ and then returned to home cage. Between mice, the arena and objects were cleaned with $70 \%$ ethanol. Exploration was defined as directing the nose to the object at a $<2 \mathrm{~cm}$ distance or touching the object with the nose or forepaws. Mice that showed unequal exploration of the two identical objects or failed to explore each object for at least $20 \mathrm{~s}$ during the familiarization session were excluded. Viewer ${ }^{3}$ video tracking system was used for data analysis.

\section{Contextual and Cued Trace Fear Conditioning Test}

Contextual and cued trace fear conditioning test was used to test the amygdala- and hippocampus-dependent associative cognition as described previously (25). Briefly, mice were acclimatized to the room for $1 \mathrm{~h}$ and habituated for $10 \mathrm{~min}$ to the conditioning chamber Automatic Reflex Conditioner (Ugo Basile, Gemonio, Italy). In the training session $24 \mathrm{~h}$ later, individual mice were subjected to the conditioning cue (a 70 $\mathrm{dB}, 670 \mathrm{~Hz}$ tone) for $20 \mathrm{~s}$, followed by a trace period of $18 \mathrm{~s}$ and a foot shock $(0.5 \mathrm{~mA}, 2 \mathrm{~s})$. This sequence was delivered 8 times at $60 \mathrm{~s}$ intervals. Thereafter, mice returned to home cage. Between mice the chamber was cleaned with $70 \%$ ethanol. The next day, contextual response was assessed in the same chamber (old context) during $3 \mathrm{~min}$. One to three hours later, the mice were placed in a new context (a plastic cylinder with striped walls and plastic floor, and novel odor of vanilla extract). After 3 min of exploration (pre-CS), the auditory cue was presented 4 times for $20 \mathrm{~s}$ at $60 \mathrm{~s}$ intervals (CS). During each session, mice were recorded and freezing behavior, defined as the absence of all body movements other than those associated with respiration, was scored manually every 5 th second. Results were expressed as the relative fraction of total time spent in freezing (\%).

\section{Brain Collection and Processing}

The mice were deeply anesthetized with thiopental [Pentothal Sodium (0.01 $\mathrm{ml} / \mathrm{g}$ body weight), Hospira, Illinois, USA] and transcardially perfused with PBS, followed by $4 \%$ paraformaldehyde (PFA) in 0.1 M PBS. Brains were removed and post-fixed in $4 \%$ PFA at $4^{\circ} \mathrm{C}$ for $24 \mathrm{~h}$ followed by $70 \%$ 
ethanol for $24 \mathrm{~h}$. Tissue was processed using an automatic tissue processor (SAKURA Tissue TeK VIP 3000, Tournai, Belgium) and embedded in paraffin. Brains were cut into $8-\mu \mathrm{m}$ serial coronal sections using a sliding microtome (Microm HM 450, Thermo Scientific, Massachusetts, USA), attached to silane coated slides and dried at room temperature (RT).

\section{Immunohistochemistry}

Neuronal nuclei (NeuN), cut like homeobox 1 (Cux-1), and T-box brain transcription factor 1 (Tbr-1) were visualized in rostral (between Bregma 1.70 and $1.34 \mathrm{~mm}$ ) and caudal (between Bregma -0.22 and $-0.82 \mathrm{~mm}$ ) motor cortex, primary and secondary somatosensory cortex by immunohistochemistry. Briefly, sections were deparaffinized and rehydrated followed by heat-induced antigen retrieval with $0.01 \mathrm{M}$ citrate buffer $(\mathrm{pH}$ $6,0.05 \%$ Tween 20) for NeuN and Cux-1, or $0.01 \mathrm{M}$ Tris$1 \mathrm{mM}$ EDTA ( $\mathrm{pH} 9,0.05 \%$ Tween 20) buffer for Tbr-1. After washing with PBS-T $(0.05 \%$ Tween 20$)$, non-specific protein binding was reduced by incubation with blocking buffer $(4 \%$ normal donkey serum in PBS-T for $1 \mathrm{~h}$ at room temperature (RT). Tissue was then incubated overnight at $4^{\circ} \mathrm{C}$ with primary antibody [anti-NeuN biotinylated (1:200, MAB 377B, Millipore, MA, USA), anti-Cux-1 (1:1,000, ab54583, Abcam), anti-Tbr$1(1: 1,000, a b 31940$, Abcam) $]$, in blocking buffer. One section per slide was incubated only with blocking buffer without primary antibody and used as a negative control. Next day, the sections were washed with PBS-T and incubated with secondary antibody [rabbit-anti mouse biotinylated Ig (1:200, E0354, DAKO, Stockholm, Sweden) for Cux-1, donkey-anti rabbit biotinylated Ig (1:200, 711-065-152, Jackson ImmunoResearch Inc., PA, USA) for Tbr-1], in blocking buffer for $1 \mathrm{~h}$ at RT. After washing, Neun immuonstained sections were incubated with Streptavidin-Cy3 (1:100, S6402, Sigma-Aldrich, Missouri, USA) in blocking buffer for $1 \mathrm{~h}$ at RT, washed, mounted with ProLong Gold (P36931, Life Technologies, CA, USA), coverslipped and dried for $24 \mathrm{~h}$ before being sealed with nail polish. For Cux-1 and Tbr-1 immunostaining, sections were incubated with avidin/biotin complex (VECTASTAIN ${ }^{\circledR}$ Elite ABC kit, PK-6100, Vector Laboratories Inc., CA, USA) followed by diaminobenzidine (DAB) Substrate Kit (SK-4100, Vector Laboratories Inc., CA, USA) according to manufacturer's instructions. After washing, sections were dehydrated (70\% $\mathrm{EtOH} 2 \mathrm{~min}, 95 \% \mathrm{EtOH} 2 \mathrm{~min}, 100 \% \mathrm{EtOH} 2 \mathrm{~min}$ ), and cleared with xylene for $5 \mathrm{~min}$. Slides were mounted with Vecta Mount medium (H-5000, Vector Laboratories Inc., CA, USA) and coverslipped.

Cells were counted using ImageJ $1.46 \mathrm{r}$ software. NeuN positive cells were counted on immunofluorescence images obtained with a $10 \mathrm{x}$ objective. Cux-1 and Tbr-1 positive cells were counted on bright field images obtained with a $20 x$ objective (Nikon Eclipse $80 \mathrm{i})$. Three sections (200 $\mu \mathrm{m}$ apart) per rostral and caudal cortex, respectively, and animal were used for the analysis and the data were presented as density $\left(\right.$ cells $\left./ \mu \mathrm{m}^{2}\right)$. Cortical thickness was measured on NeuN stained images obtained with a $4 \mathrm{x}$ objective.

\section{Morphometric Analysis of Amygdala, Hippocampus, and Brain Volume}

For the morphometric analysis, sections were stained with hematoxylin and eosin. Wide-field microscope with a $4 x$ objective (Nikon Eclipse 80i, Nikon Instruments Inc., Tokyo, Japan) was used to obtain images of 3 brain sections per mouse and level at three levels $-1.22,-1.70$, and $-2.18 \mathrm{~mm}$ relative to Bregma. ImageJ $1.46 \mathrm{r}$ software was used to trace around the hippocampus, basolateral amygdaloid nucleus, basomedial amygdaloid nucleus, medial amygdaloid nucleus post erodorsal, and the hemispheres. Volumes were calculated according to the Cavalieri's principle, where $\mathrm{V}=\Sigma \mathrm{A} \times \mathrm{P} \times \mathrm{T}$ (26).

\section{Statistical Analysis}

Statistical analyses were done with Microsoft Excel and GraphPad Prism 7.0 (GraphPad Software Inc., San Diego, CA, USA). Two-tailed unpaired Student's $t$-test was used for comparisons between two groups. Two-way Analysis of Variance (ANOVA) followed by a Tukey's multiple comparisons post-hoc test was used to analyze time and distance in the open field, time and maximum speed in the rotarod test, relative exploration time and relative visitation of the objects in the object recognition test, as well as freezing time during training and in the new context in the fear conditioning test. Differences were considered significant at $p<0.05$. Data are presented as mean \pm standard error of the mean (SEM).

\section{RESULTS}

\section{$\mathrm{C}_{3} \mathrm{R}^{-/-}$Mice Are Hyperactive and Exhibit Signs of Increased Anxiety}

To assess the overall locomotor activity, we subjected the $C 3 a R^{-/-}$and WT mice to the open field test. We found that the $C 3 a R^{-/-}$mice moved at higher speed ( $p<0.01$; Figure 1A), and spent more time in motion $(p<0.01$; Figure 1B). Both groups preferred the peripheral area of the open field box over the central area, however, the distance covered in the centrum was shorter in the $C 3 a R^{-/-}$group (Figure 1C). In contrast, in the periphery the $C 3 a R^{-/-}$mice moved more than the WT mice $(p$ $<0.01$ and $p<0.001$ for time and distance covered, respectively; Figures 1C,D). We did not observe any difference between the two groups in rearing or self-grooming activities (Figures 1E-H). Next, we assessed the motor function, coordination, and balance using the rotarod. The $C 3 a R^{-1-}$ mice performed better on the test during the first trial ( $p<0.05$ for both time and speed), but in contrast to the WT mice, their performance did not improve between trial 1 and 3 (Figures 1I,J). Jointly, these results show that the $C 3 a R^{-/-}$mice are hyperactive with signs of increased anxiety, but they do not exhibit autism-like repetitive behavior.

\section{$\mathrm{C} \mathrm{a} \mathrm{R}^{-/-}$Mice Have Impaired Short-Term Memory}

Next, we used object recognition test to assess short and long-term memory. In both familiarization and test sessions, the $C 3 a R^{-/-}$mice exhibited increased explorative behavior, as shown by total exploration time $(p<0.01, p<0.05$, and $p$ 


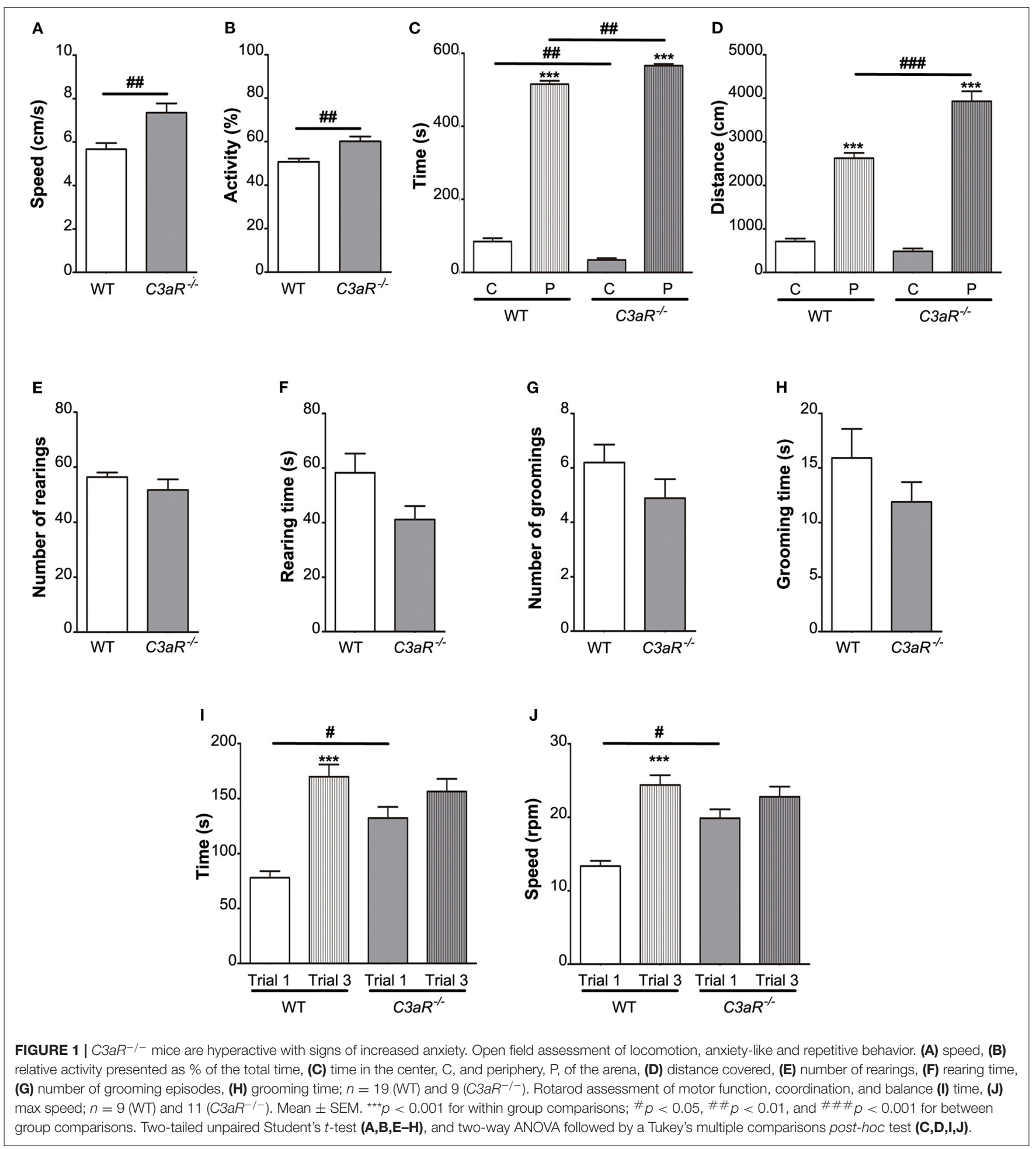

$<0.001$ for familiarization, short and long term memory test, respectively) as well as total number of visits to the objects ( $p<0.001, p<0.01$, and $p<001$ for familiarization, short and long term memory, respectively; Figures $\mathbf{2 A - K}$ ). During the familiarization session, the mice in both groups explored the two objects to an equal extent (Figures 2B,D). Mice in both groups spent more time exploring the novel object in the short as well as long-term memory test ( $p<0.001$; Figures $2 \mathrm{~F}, \mathbf{J})$, however, in the short-term memory test, in contrast to the WT group, the $C 3 a R^{-/-}$mice did not discriminate between the 


\section{Familiarization}

A

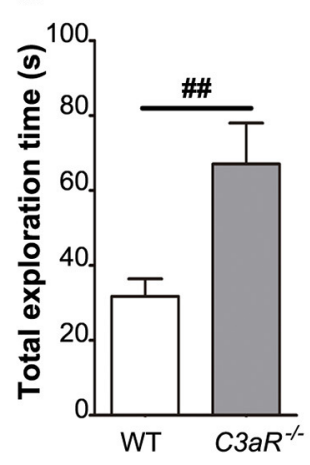

B

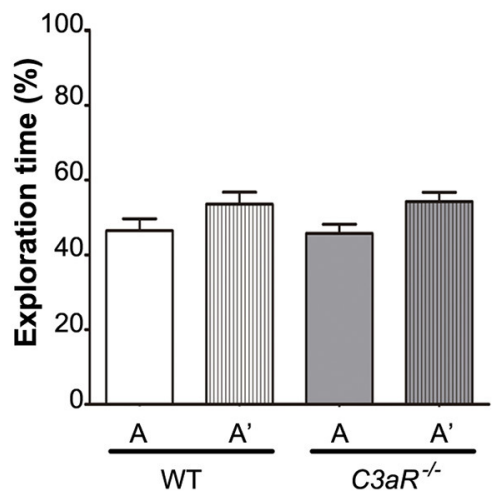

Short-term memory

E

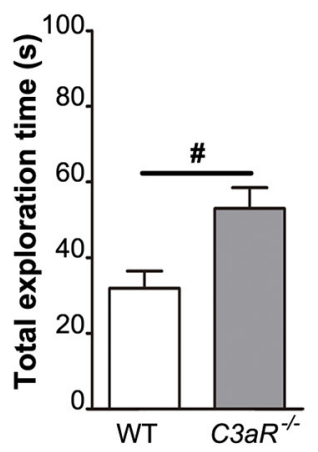

$\mathbf{F}$

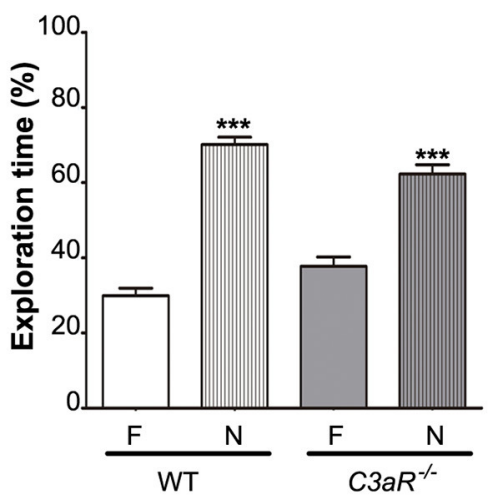

Long-term memory

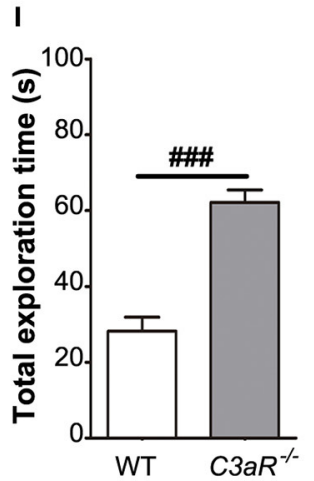

J

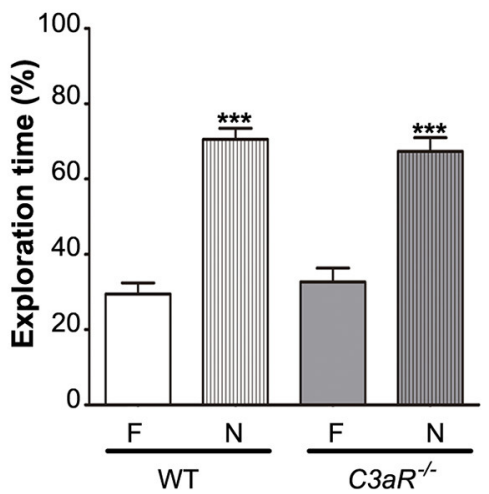

C

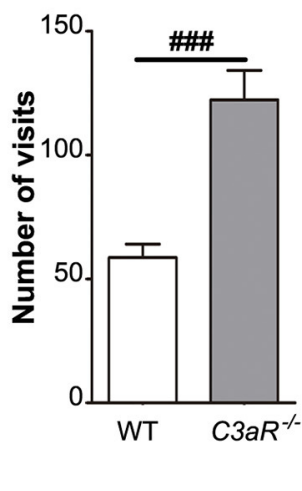

G

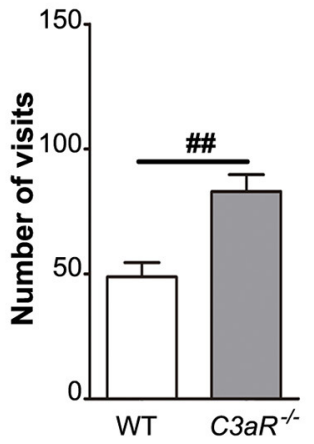

D

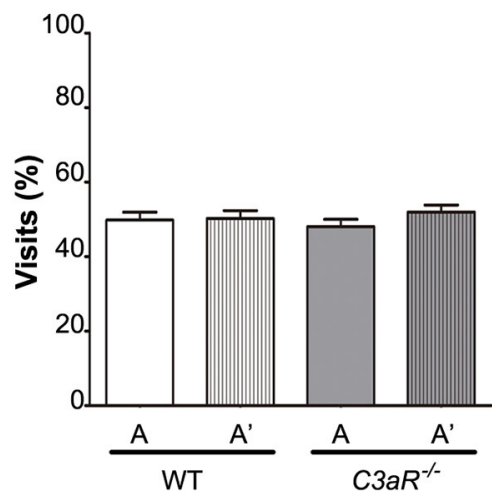

H

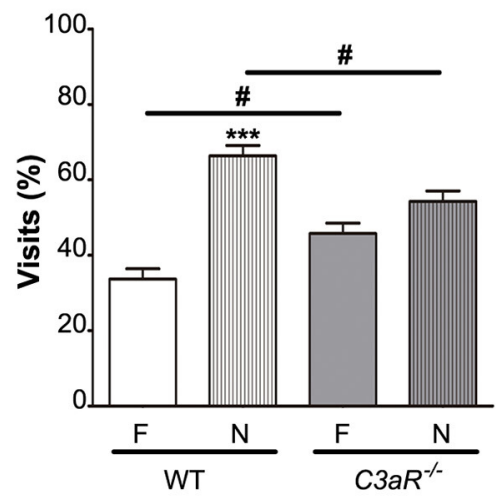

K

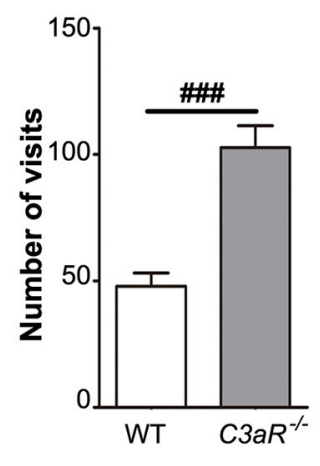

L

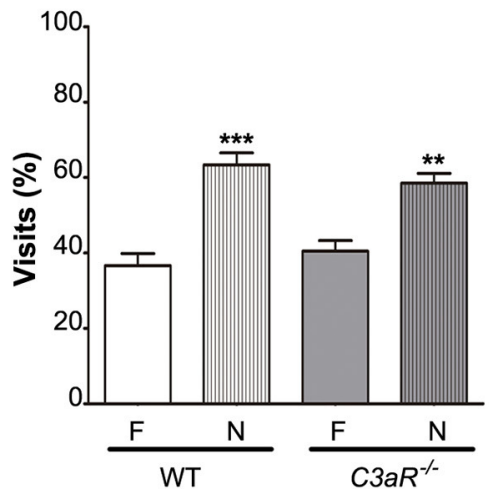

FIGURE 2 | $\mathrm{C}_{3} a R^{-1-}$ mice have impaired short-term memory. Object recognition test assessment of short and long-term memory. (A) time spent exploring individual objects, (B) relative exploration time, (C) number of visits, and (D) relative visitation of the objects during familiarization, short-term memory testing $6 \mathrm{~h}$ later $\mathbf{( E - H )}$ and long-term-memory testing $24 \mathrm{~h}$ later (I-L). A, A', identical objects used during the familiarization phase; F, familiar object; N, novel object used during the testing 
FIGURE 2 | phases. $n=11(\mathrm{WT})$ and $8\left(C 3 a R^{-/-}\right)$. Mean \pm SEM. ${ }^{* *} p<0.01$ and ${ }^{* \star *} p<0.001$ for within group comparisons; $\# p<0.05$, \#\# $p<0.01$, and $\# \# \# p$ $<0.001$ for between group comparisons. Two-tailed unpaired Student's $t$-test $(\mathbf{A}, \mathbf{C}, \mathbf{E}, \mathbf{G}, \mathbf{I}, \mathbf{K})$ and two-way ANOVA followed by a Tukey's multiple comparisons post-hoc test (B,D,F,H,J,L).

\section{Training}

A

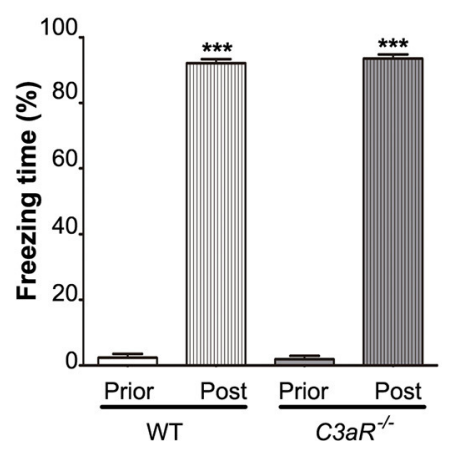

Old context

B

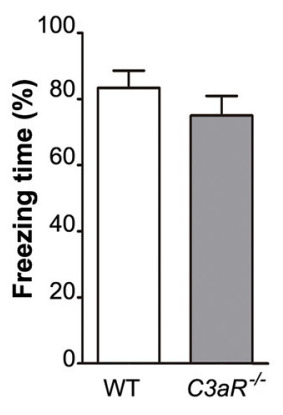

New context

C

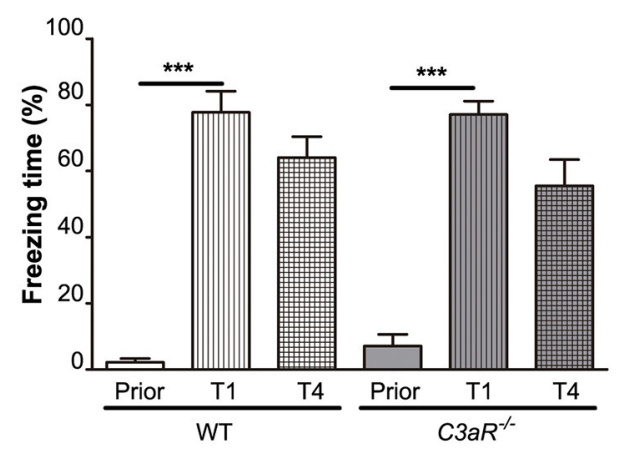

FIGURE 3 | $\mathrm{C}_{3} \mathrm{R}^{-/-}$mice exhibit normal formation and extinction of fear memory. Assessment of learning and memory by contextual/cued fear conditioning test. Relative time spent in freezing behavior during (A) training, and testing in (B) the old context without auditory cue, (C) new context in response to auditory cue. Prior, post, before and after electric shock, respectively (A); Prior, T1, T4, before and after the first and fourth exposure to auditory cue, respectively (C). $n=19$ (WT) and 9 $\left(C 3 a R^{-/-}\right)$. Mean \pm SEM. ${ }^{\star \star *} p<0.001$ for within group comparisons. Two-tailed unpaired Student's $t$-test $(\mathbf{B})$ and two-way ANOVA followed by a Tukey's multiple comparisons post-hoc test $\mathbf{( A , C )}$.

familiar and novel object in terms of the relative number of visits (Figure 2H). In the long-term memory test, there was no difference between the groups in the relative exploration of the novel vs. familiar object (Figures 2J,L). These results confirm the hyperactive behavior of the $C 3 a R^{-/-}$mice as observed in the open field test and point to the impairment in their shortterm memory.

Using fear conditioning test, we did not find any difference between the $\mathrm{C} 3 a \mathrm{R}^{-/-}$and WT mice in their freezing behavior during the training (Figure 3A) and when placed in the old context without the auditory cue (Figure 3B). None of the groups showed a reduction in freezing response between the first and the fourth trial of exposure to the auditory cue in the new context (Figure 3C). These results suggest that memory formation and extinction as assessed by fear conditioning are not altered in the $C 3 a R^{-/-}$mice.

\section{C3aR ${ }^{-/-}$Mice Exhibit Regional Alterations in Cortical Morphology}

Next, we used antibodies against NeuN, a pan-neuronal marker, ortholog of the Drosophila homeobox Cut gene, Cux-1, a transcription factor expressed predominantly in cortical neurons in layer II-IV (27), and transcription factor T-box, brain, 1 (Tbr-1), a marker of glutamatergic neurons in cortical layer VI (28), to visualize these neuronal populations on brain sections of $\mathrm{C}_{3} a \mathrm{R}^{-1-}$ and WT mice, measure the cortical thickness, and count neurons in the respective layers of the rostral and caudal motor and somatosensory cortex (Figure 4A). We did not find any difference between the groups in the thickness of the Tbr- 1 and Cux-1 cortical layers at any level (data not shown). No differences between the groups were observed in the rostral cortex (data not shown). However, the thickness of caudal motor cortex and the neuronal cell density of caudal motor cortex were reduced in the $C 3 a R^{-/-}$mice $(p<0.05$; Figures 4B-D). The $\mathrm{C} 3 \mathrm{a} \mathrm{R}^{-/-}$mice showed also higher density of Tbr-1 neurons in the caudal primary somatosensory cortex $(p<0.05$; Figures $4 \mathrm{E}, \mathbf{G})$, and higher density of Cux-1 neurons in the caudal secondary somatosensory cortex $(p<0.05$; Figures $4 \mathbf{H}, \mathbf{J})$. The thickness of the somatosensory cortex did not differ between the groups (Figures 4F,I).

\section{$\mathrm{C}_{3} \mathrm{R}^{-/-}$Mice Have Larger Amygdala and Hippocampus but Normal Brain Volume}

Next, we used hematoxylin-erythrosin stained sections to measure the volume of amygdala and hippocampus (Figure 5A), brain regions involved in the regulation of fear response, and learning and memory, respectively. While the total brain volume did not differ between the groups (Figure 5B), the $C 3 a R^{-/-}$ mice had larger amygdala $(p<0.01$ for basolateral amygdaloid nucleus, $p<0.05$ for basomedial amygdaloid nucleus, $p<$ 0.01 for medial amygdaloid nucleus post erodorsal) as well as hippocampus $(p<0.05)$, Figures 5C-G.

\section{DISCUSSION}

$\mathrm{C} 3 \mathrm{aR}$ has emerged as a novel factor in the regulation of CNS development, including embryonic neural stem cell proliferation (6) and neuronal migration $(20,21)$, however, the adult $C 3 a R^{-/-}$ mice were reported to be developmentally grossly normal with only a subtle defect in recall memory (6). Here we show that adult $C 3 a R^{-/-}$mice exhibit abnormal behavior and regional differences in brain morphology. These results point to 
A

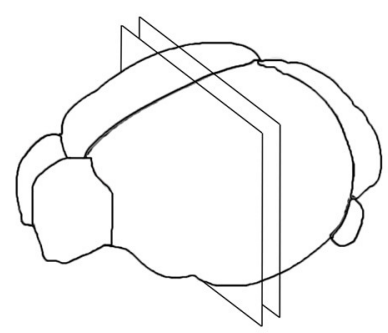

Bregma $\quad-0.22 \mathrm{~mm}$

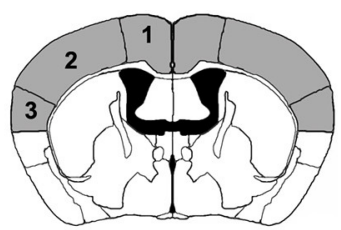

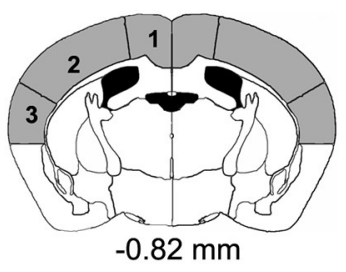

$-0.82 \mathrm{~mm}$

\section{Motor cortex (1)}

B

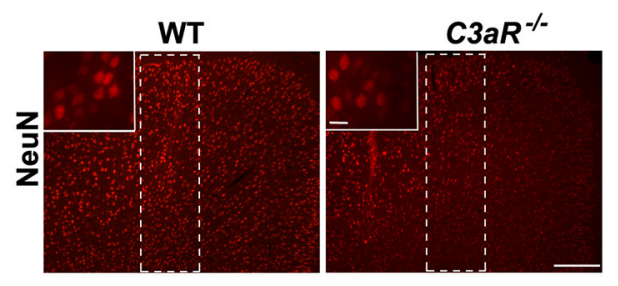

D

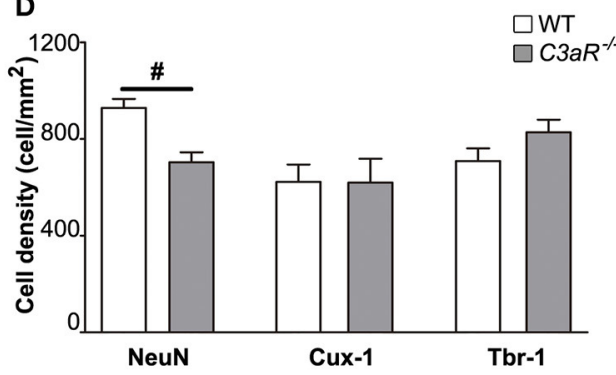

Primary somatosensory cortex (2)

E

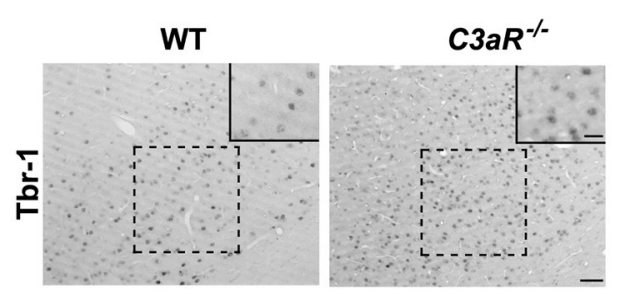

$\mathbf{F}$

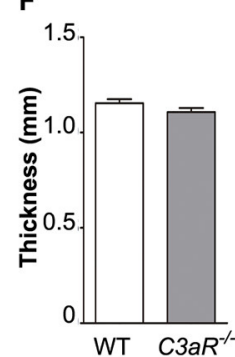

G

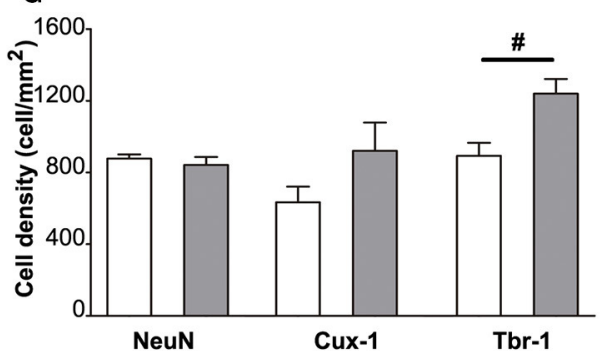

Secondary somatosensory cortex (3)

H

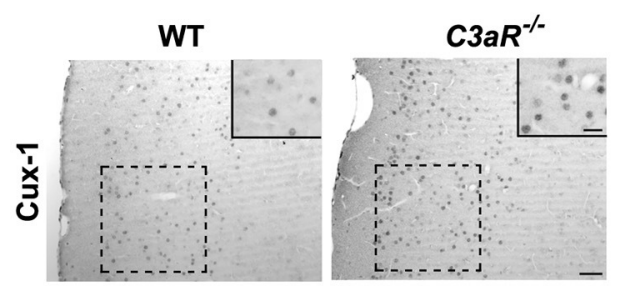

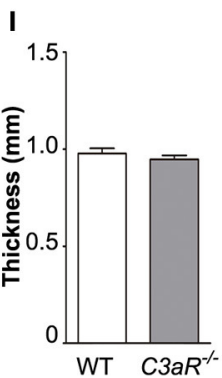

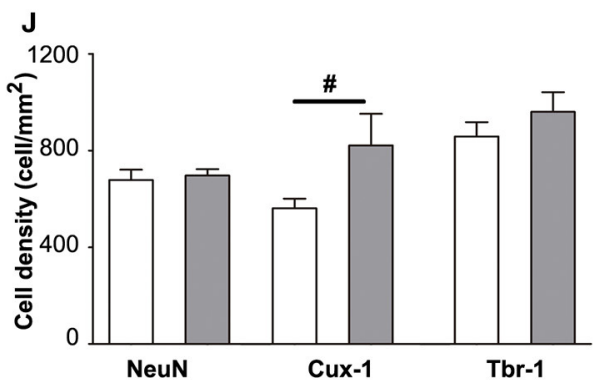

FIGURE 4 | $\mathrm{C} \mathrm{a} \mathrm{R}^{-/-}$mice exhibit regional alterations in cortical morphology. Morphological assessment of the thickness of the positive cell layer and the density of NeuN positive, Cux-1 positive, and Tbr1 positive cells in the caudal motor and somatosensory cortex. (A) Schematic illustration of the cortical regions assessed 
FIGURE 4 | including the distance from bregma. 1, motor cortex; 2, primary somatosensory cortex; 3, secondary somatosensory cortex. (B) Representative images of neurons visualized by antibody against NeuN, (C) thickness, and (D) neuronal cell density in the motor cortex. (E) Representative images of neurons visualized by antibody against Tbr-1, (F) thickness, and (G) neuronal cell density in the primary somatosensory cortex. (H) Representative images of neurons visualized by antibody against Cux-1, (I) thickness, and ( $\mathbf{J})$ neuronal cell density in the primary somatosensory cortex. Broken line rectangle in (B) and squares in (E,H) indicate the region of interest used for quantification. Insets show representative images taken with 40x objective. $n=12,10,11$ (WT) and 8, 6,7 (C3aR ${ }^{-1-}$ ) for NeuN, Tbr-1, and Cux-1 positive cells, respectively. Mean \pm SEM. ${ }^{*} p<0.05$, Two-tailed unpaired Student's t-test. Scale bars (B) $100 \mu \mathrm{m} ;(\mathbf{E}, \mathbf{H}) 50 \mu \mathrm{m}$; insets, $20 \mu \mathrm{m}$.
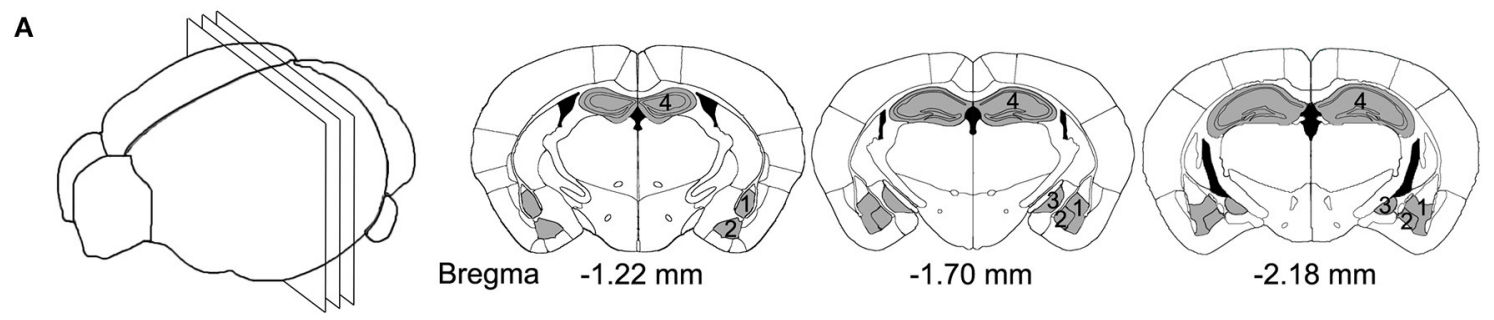

B

Brain

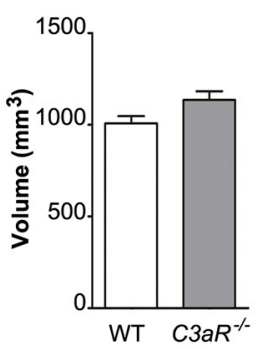

$\mathbf{F}$

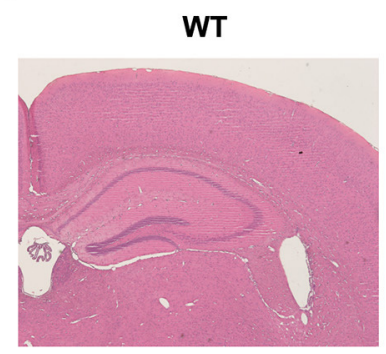

C

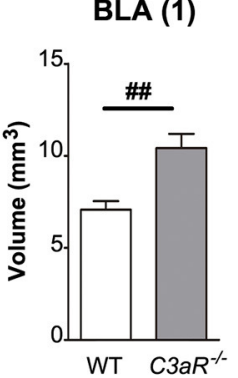

D

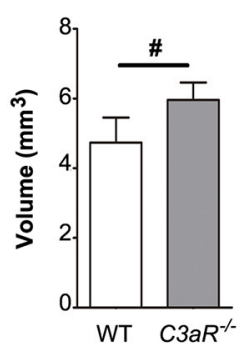

$\mathrm{CBaR}^{-1-}$

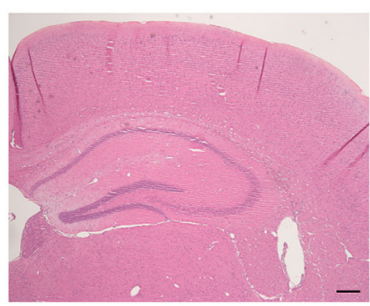

E

MEApd (3)

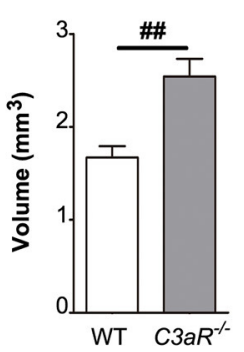

G

Hippocampus (4)

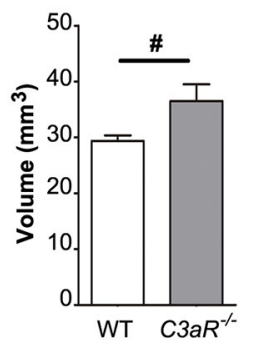

FIGURE 5 | $\mathrm{C} 3 a R^{-/-}$mice have larger amygdala and hippocampus but normal brain volume. Morphological assessment of the volume of the amygdala, the hippocampus, and the brain. (A) Schematic representation of the regions assessed and brain sections used for the quantification. Volume of (B) the whole brain between bregma $-1.22 \mathrm{~mm}$ and $-2.18 \mathrm{~mm}$. (C) BLA, basolateral amygdalar nucleus; (D) BMA, basomedial amygdalar nucleus; (E) MEApd, medial amygdalar nucleus post-erodorsal; (G) hippocampus. (F) Representative images of hippocampus at bregma $-1.70 \mathrm{~mm} ; n=11$ per group; mean \pm SEM. $\# p<0.05$ and $\# \# p$ $<0.01$. Two-tailed unpaired Student's $t$-test. 1-4 in (A) indicate the location of the respective regions in (B-E). Scale bar, $200 \mu \mathrm{m}$.

non-redundant roles of $\mathrm{C} 3 \mathrm{aR}$ signaling in brain development and function, roles that are not compensated by other factors.

First, we found that the $C 3 a R^{-/-}$mice are hyperactive as assessed by their locomotor activity in both the open field and object recognition test. In addition, the fact the $C 3 a R^{-1-}$ mice spend more time than the WT mice in the periphery could indicate increased anxiety-like behavior in the former. These behavioral abnormalities are reminiscent of the main symptoms of attention deficit hyperactivity disorder (ADHD), a neurodevelopmental disorder of complex etiology that is characterized by hyperactivity, impulsiveness, and impaired attention that can persist into adulthood, with anxiety as a common comorbidity (29). Remarkably, the $\mathrm{C}_{3 a R^{-/}}$mice had larger amygdala, including basolateral amygdala, a brain region that has been implicated in the development of anxiety in rodents (30). Hyperactivity and cognitive impairment are 
also among the behavioral features of several animal models of schizophrenia (31). While there is a mounting body of evidence supporting the role of neuroinflammation in the pathophysiology of ADHD (32) and the role of aberrant complement activity in excessive synapse elimination and the development of schizophrenia (33), our findings of larger amygdala and abnormal behavior in $C 3 a R^{-/-}$mice point to the importance of basal complement activity and signaling through $\mathrm{C} 3 \mathrm{aR}$ for normal brain development and function. The relevance of $C 3 a R^{-/-}$mice as a model of $\mathrm{ADHD}$ or schizophrenia merits further investigation.

Our results of impaired short-term memory in the C3aR $\mathrm{R}^{-/-}$ mice are in line with the report by Coulthard et al. (6). Notably, while their brain volume was comparable to that of WT mice, the $C 3 a R^{-/-}$mice had larger amygdala and hippocampus, two brain regions involved in the cognitive processes assessed in our study. Given that C3aR signaling has been shown to play a role in multiple processes regulating neurodevelopment (6, 21) as well normal neuronal function of the adult brain (5, 15), the impaired cognitive performance in mice constitutively lacking C3aR may be caused by defects in neurogenesis, neuronal migration as well as synaptic function. In addition, C3aR is expressed also on astrocytes and microglia $(7,8,11-13)$ and therefore dysfunction of glial cells, their cross-talk and communication with neurons are additional conceivable factors to consider as a potential mechanism linking $\mathrm{C} 3 \mathrm{aR}$ signaling and cognitive function.

Our results also show that despite altered morphology of amygdala, one of the brain regions involved in the regulation of fear acquisition and extinction (30), memory formation, and extinction as assessed by fear conditioning were not altered in the $C 3 a R^{-/-}$mice. Given the proposed potential overlap between fear and anxiety circuits (30), our findings of selective effect of $\mathrm{C} 3 \mathrm{aR}$ deficiency on anxiety-like behavior but not fear responses point to a distinct role of $\mathrm{C} 3 \mathrm{aR}$ signaling in the neural networks controlling the generation of fear and anxiety states.

Aberrant neuronal migration has been put forward as part of the pathophysiology of autism-spectrum disorder, a neurodevelopmental condition with brain heterotopia, disrupted neuronal minicolumns, and changes in neuronal density and volume as the main neuroanatomical and histological features $(34,35)$. Stereotyped or repetitive behaviors are among the characteristic symptoms of autism, and self-grooming is used as a measure of repetitive behavior in rodents (36). Impaired neuronal migration due to dysfunction of the complement system has been proposed as one of the mechanisms leading to autism-spectrum disorder $(21,37)$. Recent findings of social interaction deficits and repetitive behavior induced by $\mathrm{C} 3$ knockdown in the prefrontal cortex of adult mice provide support for to a role of C3 deficiency in the pathophysiology of autism-spectrum disorder (38). Here we report that the adult $\mathrm{C} 3 a R^{-/-}$mice exhibit subtle regional alterations in cortical organization, such as reduced thickness and neuronal density in the caudal motor cortex, and higher density of Tbr-1 and Cux-1 positive neurons in the caudal primary, and secondary somatosensory cortex, respectively. These abnormalities are consistent with the previously reported modulatory effects of C3a on migration of neural progenitor cells (20), the cortical migration defect caused by knockout and knockdown of C3 during embryonic development, and the rescue of this phenotype by C3aR agonist (21). Notably, ours is the first study that examined repetitive behavior in mice constitutively lacking $\mathrm{C} 3 \mathrm{aR}$. While the above findings of cortical organization abnormalities confirm the function of $\mathrm{C} 3 \mathrm{aR}$ in the development of neocortex, our observation of self-grooming behavior of the $C 3 a R^{-/-}$mice that did not differ from that of WT mice, suggests that the disturbance of cortical layering in adult $C 3 a R^{-/-}$mice is too subtle to translate into apparent autistic behavior.

In summary, we show that constitutive absence of C3aR signaling in mice leads to abnormalities in the organization and morphology of the adult neocortex, amygdala, and hippocampus. The fact that these abnormalities are associated with locomotive hyperactivity and altered cognitive functions of the $C 3 a R^{-/-}$mice may have implications for the understanding of the cellular and molecular mechanisms underlying neurodevelopmental disorders such as ADHD and autism spectrum disorder.

\section{DATA AVAILABILITY STATEMENT}

The original contributions presented in the study are publicly available. This data can be found here: https://gin.g-node.org/10. $12751 /$ g-node.k8lx52.

\section{ETHICS STATEMENT}

The animal study was reviewed and approved by Gothenburg Ethics Committee.

\section{AUTHOR CONTRIBUTIONS}

AP, MPekny, and MPekna conceptualized and designed the study. AP, RO, and JS performed the experiments. AP, MPekny, and MPekna wrote the manuscript. All authors read and approved the final version of the manuscript.

\section{FUNDING}

This work was supported by Swedish Research Council (201700991), the Swedish state under the agreement between the Swedish government and the county councils, the ALF agreement (716591), the Gothenburg Medical Society, the Swedish Brain Foundation, T. Söderberg's Foundation, E. Jacobson's Foundation, and R. and U. Amlöv's Foundation.

\section{ACKNOWLEDGMENTS}

We acknowledge the Center for Cellular Imaging at the Sahlgrenska Academy, University of Gothenburg for the use of imaging equipment and for the support from the staff. 


\section{REFERENCES}

1. Laumonnier Y, Karsten CM, Köhl J. Novel insights into the expression pattern of anaphylatoxin receptors in mice and men. Mol Immunol. (2017) 89:44-58. doi: 10.1016/j.molimm.2017.05.019

2. Coulthard LG, Woodruff TM. Is the complement activation product C3a a proinflammatory molecule? Re-evaluating the evidence and the myth. J Immunol. (2015) 194:3542-8. doi: 10.4049/jimmunol. 1403068

3. Klos A, Tenner AJ, Johswich KO, Ager RR, Reis ES, Kohl J. The role of the anaphylatoxins in health and disease. Mol Immunol. (2009) 46:275366. doi: 10.1016/j.molimm.2009.04.027

4. Hannedouche S, Beck V, Leighton-Davies J, Beibel M, Roma G, Oakeley EJ, et al. Identification of the C3a receptor (C3AR1) as the target of the VGFderived peptide TLQP-21 in rodent cells. J Biol Chem. (2013) 288:2743443. doi: 10.1074/jbc.M113.497214

5. Rahpeymai Y, Hietala MA, Wilhelmsson U, Fotheringham A, Davies I, Nilsson AK, et al. Complement: a novel factor in basal and ischemiainduced neurogenesis. EMBO J. (2006) 25:1364-74. doi: 10.1038/sj.emboj. 7601004

6. Coulthard LG, Hawksworth OA, Conroy J, Lee JD, Woodruff TM. Complement C3a receptor modulates embryonic neural progenitor cell proliferation and cognitive performance. Mol Immunol. (2018) 101:17681. doi: 10.1016/j.molimm.2018.06.271

7. Davoust N, Jones J, Stahel PF, Ames RS, Barnum SR. Receptor for the C3a anaphylatoxin is expressed by neurons and glial cells. Glia. (1999) 26:20111. doi: 10.1002/(sici)1098-1136(199905)26:3<201::aid-glia2>3.0.co;2-m

8. Van Beek J, Bernaudin M, Petit E, Gasque P, Nouvelot A, Mackenzie ET, et al. Expression of receptors for complement anaphylatoxins C3a and C5a following permanent focal cerebral ischemia in the mouse. Exp Neurol. (2000) 161:373-82. doi: 10.1006/exnr.1999.7273

9. Benard M, Gonzalez BJ, Schouft MT, Falluel-Morel A, Chan P, Vaudry $\mathrm{H}$, et al. Characterization of $\mathrm{C} 3 \mathrm{a}$ and $\mathrm{C} 5 \mathrm{a}$ Receptors in rat cerebellar granule neurons during maturation. Neuroprotective effect of C5a against apoptotic cell death. J Biol Chem. (2004) 279:43487-96. doi: 10.1074/jbc.M404 124200

10. Pedersen ED, Froyland E, Kvissel AK, Pharo AM, Skalhegg BS, Rootwelt T, et al. Expression of complement regulators and receptors on human NT2-N neurons-effect of hypoxia and reoxygenation. Mol Immunol. (2007) 44:245968. doi: 10.1016/j.molimm.2006.10.022

11. Möller T, Nolte C, Burger R, Verkhratsky A, Kettermann H. Mechanisms of $\mathrm{C} 5 \mathrm{a}$ and $\mathrm{C} 3 \mathrm{a}$ complement fragmentinduced $\left[\mathrm{Ca}^{2+}\right] \mathrm{i}$ signaling in mouse microglia. $J$ Neurosci. (1997) 17:615-24. doi: 10.1523/JNEUROSCI.17-02-00615. 1997

12. Heese $\mathrm{K}$, Hock $\mathrm{C}$, Otten $\mathrm{U}$. Inflammatory signals induce neurotropin expression in human microglial cells. $J$ Neurochem. (1998) 70:699-707. doi: 10.1046/j.1471-4159.1998.7002 0699.x

13. Shinjyo N, De Pablo Y, Pekny M, Pekna M. Complement peptide C3a promotes astrocyte survival in response to ischemic stress. Mol Neurobiol. (2016) 53:3076-87. doi: 10.1007/s12035-015-9204-4

14. Stokowska A, Pekna M. Complement C3a: shaping the plasticity of the post-stroke brain. In: Lapchak PA, Zhang JH, editors. Cellular and Molecular Approaches to Regeneration and Repair, Springer Series in Translational Stroke Research. Cham: Springer (2018). p. 521-41. doi: 10.1007/978-3-319-66679-2_26

15. Lian H, Yang L, Cole A, Sun L, Chiang AC, Fowler SW, et al. NFkappaBactivated astroglial release of complement C3 compromises neuronal morphology and function associated with Alzheimer's disease. Neuron. (2015) 85:101-15. doi: 10.1016/j.neuron.2014.11.018

16. Järlestedt K, Rousset CI, Ståhlberg A, Sourkova H, Atkins AL, Thornton $\mathrm{C}$, et al. Receptor for complement peptide C3a: a therapeutic target for neonatal hypoxic-ischemic brain injury. FASEB J. (2013) 27:3797804. doi: 10.1096/fj.13-230011

17. Stokowska A, Atkins AL, Moran J, Pekny T, Bulmer L, Pascoe MC, et al. Complement peptide C3a stimulates neural plasticity after experimental brain ischemia. Brain. (2017) 140:353-69. doi: 10.1093/brain/ aww314

18. Moran J, Stokowska A, Walker FR, Mallard C, Hagberg H, Pekna M. Intranasal C3a treatment ameliorates cognitive impairment in a mouse model of neonatal hypoxic-ischemic brain injury. Exp Neurol. (2017) 290:7484. doi: 10.1016/j.expneurol.2017.01.001

19. Pekny M, Wilhelmsson U, Tatlisumak T, Pekna M. Astrocyte activation and reactive gliosis-A new target in stroke? Neurosci Lett. (2019) 689:4555. doi: 10.1016/j.neulet.2018.07.021

20. Shinjyo N, Stahlberg A, Dragunow M, Pekny M, Pekna M. Complementderived anaphylatoxin $\mathrm{C} 3 \mathrm{a}$ regulates in vitro differentiation and migration of neural progenitor cells. Stem Cells. (2009) 27:2824-32. doi: 10.1002/stem. 225

21. Gorelik A, Sapir T, Haffner-Krausz R, Olender T, Woodruff TM, Reiner O. Developmental activities of the complement pathway in migrating neurons. Nat Commun. (2017) 8:15096. doi: 10.1038/ncomms 15096

22. Gorelik A, Sapir T, Ben-Reuven L, Reiner O. Complement C3 affects Rac1 activity in the developing brain. Front Mol Neurosci. (2018) 11:150. doi: 10.3389/fnmol.2018.00150

23. Carmona-Fontaine C, Theveneau E, Tzekou A, Tada M, Woods $\mathrm{M}$, Page KM, et al. Complement fragment C3a controls mutual cell attraction during collective cell migration. Dev Cell. (2011) 21:1026-37. doi: 10.1016/j.devcel.2011.10.012

24. Kildsgaard J, Hollmann TJ, Matthews KW, Bian K, Murad F, Wetsel RA. Targeted disruption of the C3a receptor gene demonstrates a novel protective anti-inflammatory role for $\mathrm{C} 3 \mathrm{a}$ in endotoxin shock. J Immunol. (2000) 165:5406-9. doi: 10.4049/jimmunol.165. 10.5406

25. Wilhelmsson U, Pozo-Rodrigalvarez A, Kalm M, De Pablo Y, Widestrand A, Pekna M, et al. The role of GFAP and vimentin in learning and memory. Biol Chem. (2019) 400:1147-56. doi: 10.1515/hsz-2019-0199

26. Svedin P, Hagberg H, Savman K, Zhu C, Mallard C. Matrix metalloproteinase- 9 gene knock-out protects the immature brain after cerebral hypoxia-ischemia. J Neurosci. (2007) 27:15118. doi: 10.1523/JNEUROSCI.4391-06.2007

27. Nieto M, Monuki ES, Tang H, Imitola J, Haubst N, Khoury SJ, et al. Expression of Cux-1 and Cux-2 in the subventricular zone and upper layers II-IV of the cerebral cortex. J Comp Neurol. (2004) 479:168-80. doi: 10.1002/cne. 20322

28. Hevner RF, Shi L, Justice N, Hsueh Y, Sheng M, Smiga S, et al. Tbr1 regulates differentiation of the preplate and layer 6. Neuron. (2001) 29:35366. doi: 10.1016/S0896-6273(01)00211-2

29. Biederman J. Attention-deficit/hyperactivity disorder: a selective overview. Biol Psychiatry. (2005) 57:1215-20. doi: 10.1016/j.biopsych.2004. 10.020

30. Tovote P, Fadok JP, Lüthi A. Neuronal circuits for fear and anxiety. Nat Rev Neurosci. (2015) 16:317-31. doi: 10.1038/nrn 3945

31. Jones CA, Watson DJ, Fone KC. Animal models of schizophrenia. Br J Pharmacol. (2011) 164:1162-94. doi: 10.1111/j.1476-5381.2011. 01386.x

32. Dunn GA, Nigg JT, Sullivan EL. Neuroinflammation as a risk factor for attention deficit hyperactivity disorder. Pharmacol Biochem Behav. (2019) 182:22-34. doi: 10.1016/j.pbb.2019.05.005

33. Sekar A, Bialas AR, De Rivera H, Davis A, Hammond TR, Kamitaki $\mathrm{N}$, et al. Schizophrenia risk from complex variation of complement component 4. Nature. (2016) 530:177-83. doi: 10.1038/nature 16549

34. Casanova MF. Autism as a sequence: from heterochronic germinal cell divisions to abnormalities of cell migration and cortical dysplasias. Med Hypotheses. (2014) 83:32-8. doi: 10.1016/j.mehy.2014. 04.014

35. Reiner O, Karzbrun E, Kshirsagar A, Kaibuchi K. Regulation of neuronal migration, an emerging topic in autism spectrum disorders. J Neurochem. (2016) 136:440-56. doi: 10.1111/jnc. 13403 
36. Kalueff AV, Stewart AM, Song C, Berridge KC, Graybiel AM, Fentress JC. Neurobiology of rodent self-grooming and its value for translational neuroscience. Nat Rev Neurosci. (2016) 17:45-59. doi: 10.1038/nrn.2015.8

37. Magdalon J, Mansur F, e Teles SAL, De Goes VA, Reiner O, Sertié AL. Complement system in brain architecture and neurodevelopmental disorders. Front Neurosci. (2020) 14:23. doi: 10.3389/fnins.2020. 00023

38. Fagan K, Crider A, Ahmed AO, Pillai A. Complement C3 expression is decreased in autism spectrum disorder subjects and contributes to behavioral deficits in rodents. Complex Psychiatry. (2017) 3:1927. doi: $10.1159 / 000465523$
Conflict of Interest: The authors declare that the research was conducted in the absence of any commercial or financial relationships that could be construed as a potential conflict of interest.

Copyright (๑ 2021 Pozo-Rodrigálvarez, Ollaranta, Skoog, Pekny and Pekna. This is an open-access article distributed under the terms of the Creative Commons Attribution License (CC BY). The use, distribution or reproduction in other forums is permitted, provided the original author(s) and the copyright owner(s) are credited and that the original publication in this journal is cited, in accordance with accepted academic practice. No use, distribution or reproduction is permitted which does not comply with these terms. 